\title{
Analisis Kebangkrutan Dengan Model Altman Z- Score Pada Perusahaan Sektor Industri Dasar Dan Kimia Di Bei Periode 2013-2014
}

\author{
Suci Kurniawati \\ Sekolah Tinggi Ilmu Ekonomi Indonesia Rawamangun \\ Jl. Kayu jati Raya no. 11A Rawamangun Jakarta Timur \\ suci_kurniawati@yahoo.co.id
}

\begin{abstract}
The purpose of this study is to analyze the company's financial distress on basis industry and chemical sectors as many as 57 companies using the ALTMAN Z-Score model in 2013-2014. The data which used was secondary data, such as Financial Statements of manufacturing company publication issued by Indonesian Stock Exchange (BEI) and obtained by downloading the website: www.idx.com. This study uses descriptive quantitative method. The finding of Z-Score index in basis industry and chemical sector in 2013 is occupied by PT. Intan Wijaya Internasional Tbk on chemical subsector and 2014 is occupied by PT. Alakasa Industrindo Tbk on metal subsector and others, with the first highest rank and healthy condition, whereas the last and lowest rank on wood and processing sector in 2013-2014 is PT. SLJ Global Tbk, with having financial distress condition. The findings of this study are not consistent or even in accordance with the reality which shows that the Altman method can not be used as a tool to indicate a tendency towards company's financial distress.
\end{abstract}

Keywords: financial distress, z-score, basis industry and chemical sector

\section{PENDAHULUAN}

Kebangkrutan perusahaan merupakan salah satu fenomena yang sering terjadi dalam dunia usaha baik dipengaruhi oleh pihak internal maupun eksternal perusahaan. Misalnya terjadi kenaikan biaya bahan baku, biaya upah, biaya listrik atau biaya lainnya tanpa diimbangi dengan kemampuan perusahaan, adanya produk pesaing yang lebih unggul sehingga mempengaruhi penjualan dan ketidakmampuan manajer dalam melakukan manajemen perusahaan. Kejadian tersebut secara tidak langsung akan berpengaruh terhadap penurunan kinerja perusahaan dan dapat menyebabkan perusahaan mengalami kebangkrutan. 
Untuk mengantisipasi terjadinya kebangkrutan maka perusahaan harus mempunyai persiapan dini untuk mencegah agar tidak terjadi hal yang tidak diinginkan. Perusahaan diharapkan dapat menilai kondisi perusahaan yang sedang berjalan agar memperoleh gambaran yang lebih jelas mengenai kondisi perusahaan sekarang ini, sehingga dapat mengetahui tindakan apa yang tepat untuk mempertahankan dan memperbaiki kekurangan perusahaan agar dapat bertahan dan bersaing.

Salah satu alat yang digunakan perusahaan untuk menilai kondisi perusahaan adalah laporan keuangan yang dihasilkan setiap periode. Agar perusahaan dapat mengetahui lebih jelas kondisi perusahaan sekarang ini, maka perusahaan dapat membandingkan laporan keuangan yang sekarang dengan laporan keuangan periode sebelumnya.

Rasio keuangan merupakan alat untuk menganalisis hubungan dari berbagai pos dalam laporan keuangan sebagai dasar untuk menginterpretasikan baik atau buruknya kondisi keuangan dan hasil operasi perusahaan yang diperoleh dari balance sheet dan income statement. Rasio-rasio yang digunakan umumnya meliputi Liquidity Ratio, Profitability Ratio, Efficiency Ratio, Coverage Ratio.

Seiring dengan dinamika bisnis, rasio-rasio keuangan bukan hanya untuk menginterpretasikan baik atau buruknya kondisi keuangan dan hasil operasi perusahaan tetapi dapat digunakan dalam menganalisis dan mengindikasikan kecenderungan kebangkrutan perusahaan.

Salah satu model kebangkrutan yang terbukti memberikan banyak manfaat adalah model Z-Score. Model ini dikembangkan oleh Edward I Altman seorang ekonom keuangan. Model ini merupakan pengembangan dari teknik statistik multiple discriminant yang menggabungkan efek beberapa variabel. Model Altman ini merupakan suatu model analisis keuangan yang telah banyak digunakan di Amerika Serikat.

Pada tahun 2014 ekonomi global dan kebijakan moneter Indonesia mengalami laju yang lambat karena perkembangan industri manufaktur Indonesia mengalami dilema dalam suku bunga yang tinggi 7,5\% dan kenaikan tarif dasar listrik industri per 1 mei 2014. Suku bunga dan tarif listrik yang naik menjadi beban industri manufaktur karena suku bunga akan menekan konsumsi masyarakat sehingga pembelian kendaraan bermotor yang menjadi dasar industri logam akan menurun, sedangkan kenaikan listrik dapat menambah biaya produksi. Pertumbuhan industri manufaktur tahun 2014 berada dikisaran 5\% dan pada tahun 2013 tumbuh 5,64\% yang ditopang oleh industri logam setelah industri kendaraan bermotor dan industri makanan. (http://www.kemenperin.go.id/) 
Pemerintah terus melakukan upaya strategis dalam meningkatkan daya saing dan pertumbuhan industri dalam negeri. Salah satu sektor yang dijadikan acuan pertumbuhan industri adalah kimia dan logam. Rantai nilai industri kimia terkait erat dengan sektor ekonomi produktif yaitu pangan, sandang, dan papan, serta penyediaan bahan baku berbagai industri hilir antara lain industri catdancoating, elektronik, serta otomotif.Pada sektor industri logam pemerintah terus memperkuat program hilirisasi industri berbasis mineral tambang yang mampu menggerakkan perekonomian nasional melalui peningkatan nilai tambah, perkuatan struktur industri, penyediaan lapangan kerja dan peluang usaha di dalam negeri. Industri logam dan bahan dari logam berperan pada pengembangan industri hilir terutama industri otomotif, dirgantara, permesinan dan elektronika serta infrastruktur.

Namun demikian, berbagai tantangan harus dihadapi dalam rangka mengembangkan industri nasional. Saat ini, nilai impor produk industri kimia dan logam masih tinggi sehingga produk domestik relatif kurang berdaya saing dalam lingkup regional ASEAN maupun Asia. Selain itu, banyak pabrik yang berusia relatif tua dengan teknologi proses yang kurang up-to-date, sehinggamembutuhkan dukungan revitalisasi. Disadari juga bahwa investasi pembangunan pabrik kimia dan logam membutuhkan dana sangat besar dan membutuhkan dukungan kebijakan serta insentif dan iklim usaha yang kondusif. (http://www.kemenperin.go.id/)

Sektor industri dasar dan kimia adalah salah satu sektor yang termasuk dalam cabang industri manufaktur (industri non-migas) yang menghasilkan bahan-bahan dasar yang selanjutnya akan diproses menjadi barang jadi. Perusahaan non-migas yang tercatat di Bursa Efek Indonesia (BEI) terdiri dari 3 sektor, yaitu sektor industri dasar dan kimia, sektor aneka industri, dan sektor industri barang konsumsi. Sektor industri dasar dan kimia terdapat delapan sub sektor yaitu sub sektor semen, sub sektor keramik dan porselen, sub sektor logam dan sejenisnya, sub sektor kimia, sub sektor plastik dan kemasan, sub sektor pakan ternak, kayu dan pengolahannya, serta sub sektor pulp dan kertas.

Analisis kebangkrutan ini sangatlah penting karena dapat menilai indikasi kebangkrutan perusahaan, apakah suatu perusahaan terancam bangkrut atau tidak, dimana bila terjadi kebangkrutan perusahaan dapat merugikan banyak pihak seperti manajer, investor, kreditor, bahkan karyawan tersebut.

Berdasarkan hal yang telah disampaikan di atas kemudian peneliti merasa sangat penting untuk dapat melakukan penelitian tentang bagaimanakah indikasi kebangkrutan dengan model altman z-score pada sektor industri dasar dan kimia periode 2013-2014 dan apakah model altman z-score dapat digunakan sebagai alat dalam memprediksi kecendrungan kebangkrutan perusahaan. Penelitian ini 
dilakukan dengan menganalisa kebangkrutan yang menggunakan model Altman Z-Score pada industri sektor industri dasar dan kimia yang terdaftar di BEI tahun 2014.

Adapun tujuan penelitian ini : (1) Untuk mengetahui indikasi kebangkrutan pada sektor industri industri dasar dan kimia periode 2013-2014 dengan model Altman z-score; (2) Untuk mengetahui apakah model altman z-score dapat digunakan sebagai alat dalam memprediksi kecendrungan kebangkrutan perusahaan.

\section{TINJAUAN PUSTAKA}

\subsection{Review Hasil-hasil Penelitian Terdahulu}

Penelitian tentang metode altman z-score dilakukan oleh Nuralya Usman dari skripsi Strata-1 Fakultas Ekonomi Dan Bisnis Universitas Hasanuddin Makasar pada tahun 2015 dengan judul Analisis Prediksi Kebangkrutan Perusahaan dengan Menggunakan Model Altman Z-Score pada Perusahaan Manufaktur yang Terdaftar di BEI. Hasil penelitian menunjukkan bahwa pada tahun 2013 sebanyak $54.5 \%$ perusahaan diprediksi sehat, $9.1 \%$ diprediksi di gray area dan $36.4 \%$ diprediksi bangkrut. PT Malindo Feedmill Tbk, PT Gudang Garam Tbk, PT Hanjaya Mandala Sampoerna Tbk, PT Multi Bintang Indonesia Tbk, dan PT Delta Djakarta Tbk adalah lima perusahaan yang selama periode pengamatan diprediksi sehat.

Penelitian selanjutnya dari jurnal akuntansi FE Untar yang dilakukan oleh Pasaman Silaban dari Fakultas Ekonomi dan Program Magister Manajemen Universitas HKBP Nommensen Medan pada tahun 2014 dengan judul Analisis Kebangkrutan dengan Menggunakan Model Altman Z-Score: Studi Kasus di Perusahaan Telekomunikasi. Analisis menunjukkan bahwa pada 2010-2012 kondisi kesehatan perusahaan tidak baik. Pada tahun 2010 perusahaan berada di zona abu-abu, maka tahun depan kondisi perusahaan menurun, dan pada tahun 2012 itu pada kondisi tidak sehat/ bangkrut. Telkom dalam keadaan sehat dan meningkat setiap tahun, Indosat berada di zona yang tidak sehat dengan z-score cenderung meningkat setiap tahun.

Penelitian selanjutnya dari jurnal akuntansi FE Untar yang dilakukan oleh Ketut Asmara Jaya dari STIE Sailendra Jakarta pada tahun 2014 dengan judul Laporan Keuangan Merupakan Alat Dalam Memprediksi Kecendrungan Terjadinya Kebangkrutan Perusahaan Dengan Menggunakan Model ALTMAN: Study Analisis. Hasil dari penelitian ini bahwa model Altman dapat digunakan sebagai alat dalam memprediksi kecendrungan kebangkrutan perusahaan. 


\subsection{Rasio Keuangan}

Rasio keuangan adalah angka yang diperoleh dari hasil perbandingan dari satu pos laporan keuangan dengan pos lainnya yang mempunyai hubungan yang relevan dan signifikan (berarti). (Sofyan Syafri Harahap, 2006; 297).

Rasio keuangan adalah perhitungan yang dilakukan untuk menstandarisasikan, menganalisis dan membandingkan data keuangan yang dinyatakan hubungan. (Fraser \& ormiston, 2008; 346).

Dari beberapa pengertian di atas, penulis menyimpulkan bahwa rasio keuangan adalah angka-angka yang dihasilkan dari perbandingan pos-pos tertentu dengan pos lain yang ada dalam laporan keuangan dan juga merupakan hubungan matematis antara satu kuantitas dengan kuantitas lainnya.

\subsection{Analisis Altman}

Banyak penelitian telah dilakukan untuk mendapatkan model analisis yang merupakan gabungan beberapa rasio keuangan. Diantarnya penelitian yang dilakukan oleh Edward I Altman tahun 1966 untuk memprediksi kebangkrutan suatu perusahaan. Dalam studinya, Altman mengambil sampel 66 perusahaan dimana setengah dari sampel merupakan perusahaan yang telah bangkrut. Berdasarkan model Multiple Discriminant Analysis, koefisien dari kelima rasio keuangan kemudian ditentukan. Penjumlahan dan perkalian antara koefisien dengan rasio keuangan menghasilkan nilai multivatiate. Oleh Altman, nilai multivatiate ini dinamakan Z-Score.

Model Z-Score Altman dapat diuraikan sebagai berikut:

$Z=1.2 \times 1+1.4 \times 2+3.3 \times 3+0.6 \times 4+1.0 \times 5($ Altman, 1968)

\section{Dimana:}

$\mathrm{X} 1=$ Working Capital $/$ Total Assets

$\mathrm{X} 2=$ Retained Earnings $/$ Total Assets

$\mathrm{X} 3=$ EBIT $/$ Total Assets

X4= Market Value Equity / Book Value of Total Liabilities

X5 = Sales $/$ Total Assets

\section{Dengan :}

\section{Z-Score Indikasi}

$\begin{array}{ll}<1.81 & \text { Bangkrut } \\ 1.81-2.99 & \text { Grey Area / zone of ignorace } \\ >2.99 & \text { Tidak Bangkrut }\end{array}$


Model Z-Score tersebut tidak didesain untuk digunakan dalam setiap situasi. Terdapat 2 jenis model Z-Score lain, yang diperuntukkan bagi prediksi kebangkrutan perusahaan manufaktur tertutup atau non public dan perusahaan non manufaktur. yakni:

Rasio yang digunakan pada model Z-Score memiliki beberapa keterbatasan

a. Rasio untuk Market Value dibagi dengan Total Liabilities (Variabel X4). Jika perusahaan tersebut bukan merupakan perusahaan yang telah go public, maka tidak ada Market Value of Equity.

b. Rasio untuk Asset Turnover (X3), yang diperoleh dengan membagi sales dengan total assets pada akhir tahun. Rasio ini secara signifikan dapat sangatberbeda berdasarkan jenis industrinya.

Untuk mengatasi kedua masalah tersebut, Altman melakukan modifikasi terhadap model Z-Score. Modifikasi pertama dikembangkan Altman untuk memperluas penggunaan bagi perusahaan non-public atau perusahaan privat. Dalam model baru ini, variabel dihitung dengan menggunakan nilai buku ekuitas dibagi dengan nilai buku hutang. Oleh Altman modifikasi pertama ini dinamakan $Z$-Score the private firm version atau The $Z$ ' ( $Z$ Prime) version. Model baru ini dapat diuraikan dalam rumus berikut:

\section{4)}

$$
Z^{\prime}=0.717 \times 1+0.847 \times 2+3.107 \times 3+0.420 \times 4+0.998 \times 5(\text { Altman, }
$$

$$
\begin{aligned}
& \text { Dimana: } \\
& \text { X1= Working Capital } / \text { Total Assets } \\
& \text { X2 = Retained Earnings } / \text { Total Assets } \\
& \text { X3 = EBIT } / \text { Total Assets } \\
& \text { X4= Net Worth } / \text { Total Liabilities } \\
& \text { X5 = Sales / Total Assets }
\end{aligned}
$$

\section{Dengan :}

$\begin{array}{ll}\text { Z-Score } & \text { Indikasi } \\ <1.23 & \text { Bangkrut } \\ 1.23-2.90 & \text { Grey Area / zone of ignorace } \\ >2.90 & \text { Tidak Bangkrut }\end{array}$

Modifikasi kedua dilakukan untuk memperluas penggunaan model bagi perusahaan non manufaktur. Dalam model ini, variabel (Rasio perputaran asset) dihilangkan karena salah satu unsurnya, yaitu tingkat penjualan, diyakini sangat dipengaruhi oleh jenis industri perusahaan. Modifikasi terhadap model Altman 
yang terakhir ini dinamakan The Four Variable Model atau $Z$ '” ( $Z$ doubleprime). Model baru ini dapat diuraikan dalam rumusnya sebagai berikut:

$$
Z "=6.56 \times 1+3.26 \times 2+6.72 \times 3+1.05 \times 4
$$

\section{Dimana:}

$$
\begin{aligned}
& \text { X1 }=\text { Working Capital } / \text { Total Assets } \\
& \text { X2 }=\text { Retained Earnings } / \text { Total Assets } \\
& \text { X3 }=\text { EBIT } / \text { Total Assets } \\
& \text { X4 }=\text { Net Worth } / \text { Total Liabilities }
\end{aligned}
$$

Dengan :

$\begin{array}{ll}\text { Z-Score } & \text { Indikasi } \\ <1.10 & \text { Bangkrut } \\ 1.10-2.60 & \text { Grey Area / zone of ignorace } \\ >2.60 & \text { Tidak Bangkrut }\end{array}$

Hal yang menarik mengenai Z-Score adalah keandalannya sebagai alat analisis tanpa memperhitungkan ukuran perusahaan. Meskipun seandainya perusahaan dalam kondisi sangat makmur, bila Z-Score mulai menurun secara tajam, lonceng peringatan harus berdering. Atau, jika perusahaan baru saja survive, Z-Score dapat digunakan untuk membantu mengevaluasi dampak yang telah diperhitungkan dari perubahan upaya-upaya manajemen perusahaan.

\section{METODE PENELITIAN}

\subsection{Lokasi Penelitian}

Penelitian ini dilakukan di Bursa Efek Indonesia (BEI) yang terletak di Jln. Jendral Sudirman Kav 52-53, Jakarta Selatan.

\subsection{Variabel Penelitian}

Dalam penelitian ini ada dua variabel yaitu Variabel Terikat (DependentVariable) dan Variabel Bebas (Independent Variable), yaitu dalam penelitian ini yang menjadi variabel terikat adalah status kebangkrutan perusahaan dan variabel Bebas (Independent Variable) variabel-variabel rasionya adalah sebagai berikut:

\begin{tabular}{lll} 
Variabl Konsep variable & Skala \\
$\mathrm{e}$ & \\
\hline
\end{tabular}




\begin{tabular}{llll}
\hline X1 & Likuiditas & Rasio \\
X2 & Profitabilitas dalam periode & Rasio \\
& tertentu & \\
X3 & Profitabilitas & Rasio \\
X4 & Struktur keuangan & Rasio \\
X5 & Perputaran modal & Rasio
\end{tabular}

\section{Model Penelitian}

Perhitungan Z-Score dimulai dengan menghitung variabel-variabel yang dipergunakan dan kemudian memasukan nilai variabel tersebut kedalam Z-Score sehingga mendapatkan nilai Z. Variabel tersebut terdiri dari:

1. $\mathrm{X} 1=$ Liquidity Ratio,

2. $\mathrm{X} 2=$ Age of Firm and Cumulative profitabilitas Rasio,

3. $\mathrm{X} 3=$ Profitability Ratio,

4. $\mathrm{X} 4=$ Financial Structure Ratio,

5. $\mathrm{X} 5=$ Capital Turnover Ratio.

Z-Score dapat dihitung dengan cara sebagai berikut :

Z-Score $=0,717 \mathrm{X} 1+0,847 \mathrm{X} 2+3,107 \mathrm{X3}+\mathbf{0 , 4 2 0 X 4}+\mathbf{0 , 9 9 8 X 5}$

\section{Dimana :}

$\mathrm{X} 1=($ Current Asset - Current Liabilities $) /$ Total Asset

$\mathrm{X} 2$ = Retained Earning / Total Asset

$\mathrm{X} 3=$ EBIT $/$ Total Asset

X4 = Market Value Equity / book value of Total Debt

X5 = Sales $/$ Total Asset

Dengan :

\section{Z-Score Indikasi}

$<1.81 \quad$ Bangkrut

1.81 - 2.99 Grey Area / zone of ignorance

$>2.99 \quad$ Tidak Bangkrut

\subsection{Pengumpulan Data}

Data yang digunakan dalam penelitian ini merupakan data kuantitatif. Sumber datanya berupa data sekunder, dimana data sekunder ini berupa data Laporan Keuangan Publikasi Perusahaan industri dasar dan kimia yang diterbitkan Bursa Efek Indonesia dan diperoleh dari media internet dengan mendownload melalui website: $\underline{\text { www.idx.com. }}$ 
Untuk melengkapi kajian pustaka yang relevan dalam penelitian ini dikumpulkan data atau informasi dari berbagai sumber bacaan yakni diperoleh dari skripsi, jurnal-jurnal, artikel, Koran, buku, dll. Peneliti mengumpulkan, mempelajari dan mencatat data-data yang diperlukan dan diperoleh dari sumber yang berbeda-beda dari perpustakaan STEI maupun perpustakaan lain.

Teknik yang digunakan dalam mengumpulkan data adalah penelitian kepustakaan (Library research). Serta observasi dalam mengamati langsung objek penelitian untuk mendapatkan kenyataan yang sesungguhnya dari objek yang diperoleh. Dengan melalui pengamatan dengan penelitian lapangan (field research) ini peneliti ingin mengetahui uji konsistensi, sehingga peneliti dapat data yang akurat dan relevan.

\subsection{Populasi Penelitian}

Populasi yang digunakan dalam penelitian ini adalah perusahaan-perusahaan yang bergerak dalam bidang sector industri dasar dan kimia yang telah terdaftar di Bursa Efek Indonesia (BEI) pada periode 2013-2014.

\subsection{Sampel dan Sampling Penelitian}

Teknik pengambilan sampel yang digunakan pada penelitian ini adalah purposive sampling, yaitu sampel yang dipilih secara cermat sehingga relevan dengan rancangan penelitian dan diharapkan dapat mewakili masing-masing karateristik populasi, dengan kriteria sebagai berikut:

1) Perusahaan termasuk dalam industri dasar dan kimia yang ada di Indonesia.

2) Perusahaan mempublikasikan laporan keuangan yang lengkap tersedia selama periode 2013-2014.

3) Perusahaan tersebut tidak dalam keadaan merger maupun likuidasi.

Sampel yang digunakan dalam penelitian ini adalah 57 perusahaan industri dasar dan kimia. Berikut sampel yang digunakan yaitu :

Tabel 3.1. Nama Sampel yang digunakan

\begin{tabular}{cccc} 
& Kode & Sektor & Nama \\
\hline 1 & INTP & & PT. Indocement Tunggal Prakarsa \\
Tbk
\end{tabular}




\begin{tabular}{|c|c|c|c|}
\hline 5 & $\begin{array}{l}\text { AMF } \\
\text { G }\end{array}$ & \multirow{6}{*}{$\begin{array}{l}\text { subsektor keramik, } \\
\text { porselen, kaca }\end{array}$} & PT. Asahimas Flat Glass Tbk \\
\hline 6 & $\begin{array}{c}\mathrm{ARN} \\
\mathrm{A}\end{array}$ & & PT. Arwana Citramulia Tbk \\
\hline 7 & IKAI & & $\begin{array}{c}\text { PT. Intikeramik Alamasri Industri } \\
\text { Tbk }\end{array}$ \\
\hline 8 & KIAS & & $\begin{array}{l}\text { PT. Keramik Indonesia Assosiasi } \\
\text { Tbk }\end{array}$ \\
\hline 9 & MLIA & & PT. Mulia Industrindo Tbk \\
\hline 10 & TOTO & & PT. Surya Toto Indonesia Tbk \\
\hline 11 & ALKA & \multirow{15}{*}{$\begin{array}{c}\text { subsektor logam \& } \\
\text { sejenisnya }\end{array}$} & PT. Alakasa Industrindo Tbk \\
\hline 12 & ALMI & & $\begin{array}{l}\text { PT. Alumindo Light Metal } \\
\text { Industry Tbk }\end{array}$ \\
\hline 13 & BAJA & & PT. Sarana Central Bajatama Tbk \\
\hline 14 & BTON & & PT. Beton Jaya Manunggal Tbk \\
\hline 15 & CTBN & & PT. Citra Tubindo Tbk \\
\hline 16 & GDST & & PT. Gunawan Dianjaya Steel Tbk \\
\hline 17 & INAI & & PT. Indal Aluminium Industry Tbk \\
\hline 18 & JKSW & & $\begin{array}{c}\text { PT. Jakarta Kyoei Steel Works } \\
\text { Tbk }\end{array}$ \\
\hline 19 & JPRS & & PT. Jaya Pari Steel Tbk \\
\hline 20 & KRAS & & PT. Krakatau Steel Tbk \\
\hline 21 & LION & & PT. Lion Metal Works Tbk \\
\hline 22 & $\begin{array}{c}\text { LMS } \\
\mathrm{H}\end{array}$ & & PT. Lionmesh Prima Tbk \\
\hline 23 & NIKL & & PT. Pelat Timah Nusantara Tbk \\
\hline 24 & PICO & & PT. Pelangi Indah Canindo Tbk \\
\hline 25 & TBMS & & PT. Tembaga Mulia Semanan Tbk \\
\hline 26 & BRPT & \multirow{8}{*}{ subsektor kimia } & PT. Barito Pacific Tbk \\
\hline 27 & BUDI & & PT. Budi Starch \& Sweetener Tbk \\
\hline 28 & DPNS & & PT. Duta Pertiwi Nusantara Tbk \\
\hline 29 & $\begin{array}{c}\text { EKA } \\
\text { D }\end{array}$ & & PT. Ekadharma International Tbk \\
\hline 30 & INCI & & $\begin{array}{c}\text { PT. Intan Wijaya Internasional } \\
\text { Tbk }\end{array}$ \\
\hline 31 & SRSN & & PT. Indo Acidatama Tbk \\
\hline 32 & TPIA & & $\begin{array}{c}\text { PT. Chandra Asri Petrochemical } \\
\text { Tbk }\end{array}$ \\
\hline 33 & UNIC & & PT. Unggul Indah Cahaya Tbk \\
\hline 34 & $\begin{array}{c}\mathrm{AKK} \\
\mathrm{U}\end{array}$ & $\begin{array}{c}\text { subsektor plastik \& } \\
\text { kemasan }\end{array}$ & PT. Alam Karya Unggul Tbk \\
\hline
\end{tabular}




\begin{tabular}{|c|c|c|c|}
\hline 35 & APLI & & PT. Asiaplast Industries Tbk \\
\hline 36 & $\begin{array}{c}\text { BRN } \\
\text { A }\end{array}$ & & PT. Berlina Tbk \\
\hline 37 & FPNI & & PT. Lotte Chemical Titan Tbk \\
\hline 38 & IGAR & & $\begin{array}{c}\text { PT. Champion Pacific Indonesia } \\
\text { Tbk }\end{array}$ \\
\hline 39 & IMPC & & PT. Impack Pratama Industri Tbk \\
\hline 40 & IPOL & & $\begin{array}{c}\text { PT. Indopoly Swakarsa Industry } \\
\text { Tbk }\end{array}$ \\
\hline 41 & SIAP & & PT. Sekawan Intipratama Tbk \\
\hline 42 & SIMA & & PT. Siwani Makmur Tbk \\
\hline 43 & TRST & & PT. Trias Sentosa Tbk \\
\hline 44 & YPAS & & PT. Yanaprima Hastapersada Tbk \\
\hline 45 & CPIN & \multirow{3}{*}{ subsektor pakan ternak } & $\begin{array}{c}\text { PT. Charoen Pokphand Indonesia } \\
\text { Tbk }\end{array}$ \\
\hline 46 & JPFA & & PT. Japfa Comfeed Indonesia Tbk \\
\hline 47 & MAIN & & PT. Malindo Feedmill Tbk \\
\hline 48 & SULI & \multirow{2}{*}{$\begin{array}{l}\text { subsektor kayu \& } \\
\text { pengolahannya }\end{array}$} & PT. SLJ Global Tbk \\
\hline 49 & TIRT & & $\begin{array}{c}\text { PT. Tirta Mahakam Resources } \\
\text { Tbk }\end{array}$ \\
\hline 50 & $\begin{array}{c}\text { ALD } \\
\mathrm{O}\end{array}$ & \multirow{8}{*}{ subsektor pulp \& kertas } & PT. Alkindo Naratama Tbk \\
\hline 51 & DAJK & & $\begin{array}{c}\text { PT. Dwi Aneka Jaya Kemasindo } \\
\text { Tbk } \\
\end{array}$ \\
\hline 52 & $\begin{array}{c}\text { FAS } \\
\text { W }\end{array}$ & & PT. Fajar Surya Wisesa Tbk \\
\hline 53 & INKP & & PT. Indah Pulp \& Paper Tbk \\
\hline 54 & INRU & & PT. Toba Pulp Lestari Tbk \\
\hline 55 & KBRI & & $\begin{array}{l}\text { PT. Kertas Basuki Rachmat } \\
\text { Indonesia Tbk }\end{array}$ \\
\hline 56 & SPMA & & PT. Suparma Tbk \\
\hline 57 & TKIM & & $\begin{array}{c}\text { PT. Pabrik Kertas Twiji Kimia } \\
\text { Tbk }\end{array}$ \\
\hline
\end{tabular}

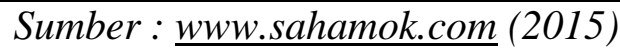

\subsection{Metode Analisis Data}

Metode analisis yang digunakan oleh peneliti untuk mengolah data yaitu dengan menggunakan Metode Altman Z-Score dan uji tingkat kesesuaian dengan kenyataan sebenarnya. 


\subsection{Metode Altman Z-Score}

Tahapan yang digunakan dalam melakukan penelitian untuk menentukan kondisi keuangan dengan metode Altman Z-Score yaitu:

1. Menghitung rasio keuangan

Variabel tersebut terdiri dari:

1. $\mathrm{X} 1=$ Liquidity Ratio,

2. $\mathrm{X} 2=$ Age of Firm and Cumulative profitabilitas Rasio,

3. $\mathrm{X} 3=$ Profitability Ratio,

4. $\quad \mathrm{X} 4=$ Financial Structure Ratio,

5. $\quad \mathrm{X} 5=$ Capital Turnover Ratio.

\section{Dimana :}

$\mathrm{X} 1=($ Current Asset - Current Liabilities $) /$ Total Asset

$\mathrm{X} 2=$ Retained Earning / Total Asset

$\mathrm{X} 3=$ EBIT $/$ Total Asset

$\mathrm{X} 4$ = Market Value Equity / book value of Total Debt

X5 = Sales $/$ Total Asset

2. Melakukan perhitungan dengan analisis diskriminan yang ditemukan Altmanmelalui rumus. Z-Score dapat dihitung dengan cara sebagai berikut :

$$
Z-S c o r e=0,717 \times 1+0,847 \times 2+3,107 X 3+0,420 \times 4+0,998 \times 5
$$

1. Melakukan interpretasi dari hasil perhitungan Z-Score yang telah diolah. Hal ini tentunya dengan batas ketentuan yang telah ditentukan, yaitu:
1. Z-Score
2. Indikasi
3. $<1.81$
4. Bangkrut
5. $1.81-2.99$
6. Grey Area / zone of
7. $>2.99$
8. Tidak Bangkrut

2. Membuat index peringkat/ rangking sesuai nilai z-score.

\subsection{Model Analisis Historis}

Dalam penelitian ini, peneliti menggunakan analisis historis untuk mengetahui tingkat kesesuaian dengan kenyataan sebenarnya.

\section{HASIL PENELITIAN DAN PEMBAHASAN}

5.1. Analisis model Altman Z-Score 
Tabel 4.1. Hasil index peringkat indikasi Sehat tahun 2013

\begin{tabular}{|c|c|c|c|}
\hline SEKTOR & Kode & Z-Score & $\underset{\mathbf{t}}{\text { Peringka }}$ \\
\hline subsektor kimia & INCI & 5,2488 & $\mathbf{1}$ \\
\hline subsektor logam \& & ALK & & \\
\hline sejenisnya & A & 4,7677 & 2 \\
\hline $\begin{array}{l}\text { subsektor logam \& } \\
\text { sejenisnya }\end{array}$ & JPRS & 4,0087 & 3 \\
\hline $\begin{array}{l}\text { subsektor keramik, porselen, } \\
\text { kaca }\end{array}$ & KIAS & 3,8184 & 4 \\
\hline subsektor kimia & DPNS & 3,5497 & 5 \\
\hline $\begin{array}{l}\text { subsektor logam \& } \\
\text { sejenisnya }\end{array}$ & TBMS & 3,4831 & 6 \\
\hline subsektor plastik \& kemasan & IGAR & 3,4237 & 7 \\
\hline $\begin{array}{l}\text { subsektor logam \& } \\
\text { sejenisnya }\end{array}$ & $\begin{array}{l}\text { LMS } \\
\mathrm{H}\end{array}$ & 3,3953 & 8 \\
\hline subsektor pakan ternak & CPIN & 3,1718 & 9 \\
\hline
\end{tabular}

Pada tabel 4.1. tersebut dengan kode INCI yakni PT. Intan Wijaya Internasional Tbk pada subsektor kimia memiliki nilai z-score 5,2488 dengan indikasi diatas 2,99 yang terletak di posisi yang sehat dan menduduki peringkat/ rangking pertama tertinggi pada perusahaan manufaktur tahun 2013, sedangkan dengan kode CPIN yakni PT. Charoen Pokphand Indonesia Tbk pada subsektor pakan ternak memiliki nilai z-score 3,1718 dengan indikasi diatas 2,99 yang terletak di posisi yang sehat dan menduduki peringkat/ rangking ke 9 pada tahun 2013.

Tabel 4.2. Hasil index peringkat indikasi Sehat tahun 2014

\begin{tabular}{|c|c|c|c|}
\hline SEKTOR & Kode & $\begin{array}{l}\text { Z- } \\
\text { Score }\end{array}$ & $\underset{t}{\text { Peringka }}$ \\
\hline $\begin{array}{lll}\begin{array}{l}\text { subsektor } \\
\text { sejenisnya }\end{array} & \text { logam } & \& \\
\end{array}$ & $\begin{array}{l}\text { ALK } \\
\text { A }\end{array}$ & 5,3204 & 1 \\
\hline subsektor kimia & INCI & 5,1253 & 2 \\
\hline subsektor plastik \& kemasan & SIAP & 5,0890 & 3 \\
\hline $\begin{array}{l}\text { subsektor keramik, porselen, } \\
\text { kaca }\end{array}$ & KIAS & 4,2866 & 4 \\
\hline subsektor plastik \& kemasan & IGAR & 3,7644 & 5 \\
\hline subsektor & JPRS & 3,7240 & 6 \\
\hline
\end{tabular}


sejenisnya

subsektor semen

SMB

$\begin{array}{lll}\mathrm{R} & 3,5237 & 7\end{array}$

subsektor logam \& TBM

sejenisnya

S $\quad 3,3968$

8

subsektor logam

sejenisnya

\& LMS

H $\quad 3,2977 \quad 9$

Sumber: olah data

Pada tabel 4.2. tersebut dengan kode ALKA yakni PT. Alakasa Industrindo Tbk pada subsektor logam dan sejenisnya memiliki nilai z-score 5,3204 dengan indikasi diatas 2,99 yang terletak di posisi yang sehat dan menduduki peringkat/ rangking pertama tertinggi pada perusahaan industri dasar dan kimia tahun 2014, sedangkan dengan kode LMSH yakni PT. Lionmesh Prima Tbk pada subsektor logam dan sejenisnya memiliki nilai z-score 3,2977 dengan indikasi diatas 2,99 yang terletak di posisi yang sehat dan menduduki peringkat/ rangking ke 9 pada perusahaan industri dasar dan kimia tahun 2014.

Tabel 4.3. Hasil index peringkat indikasi Grey Area tahun 2013

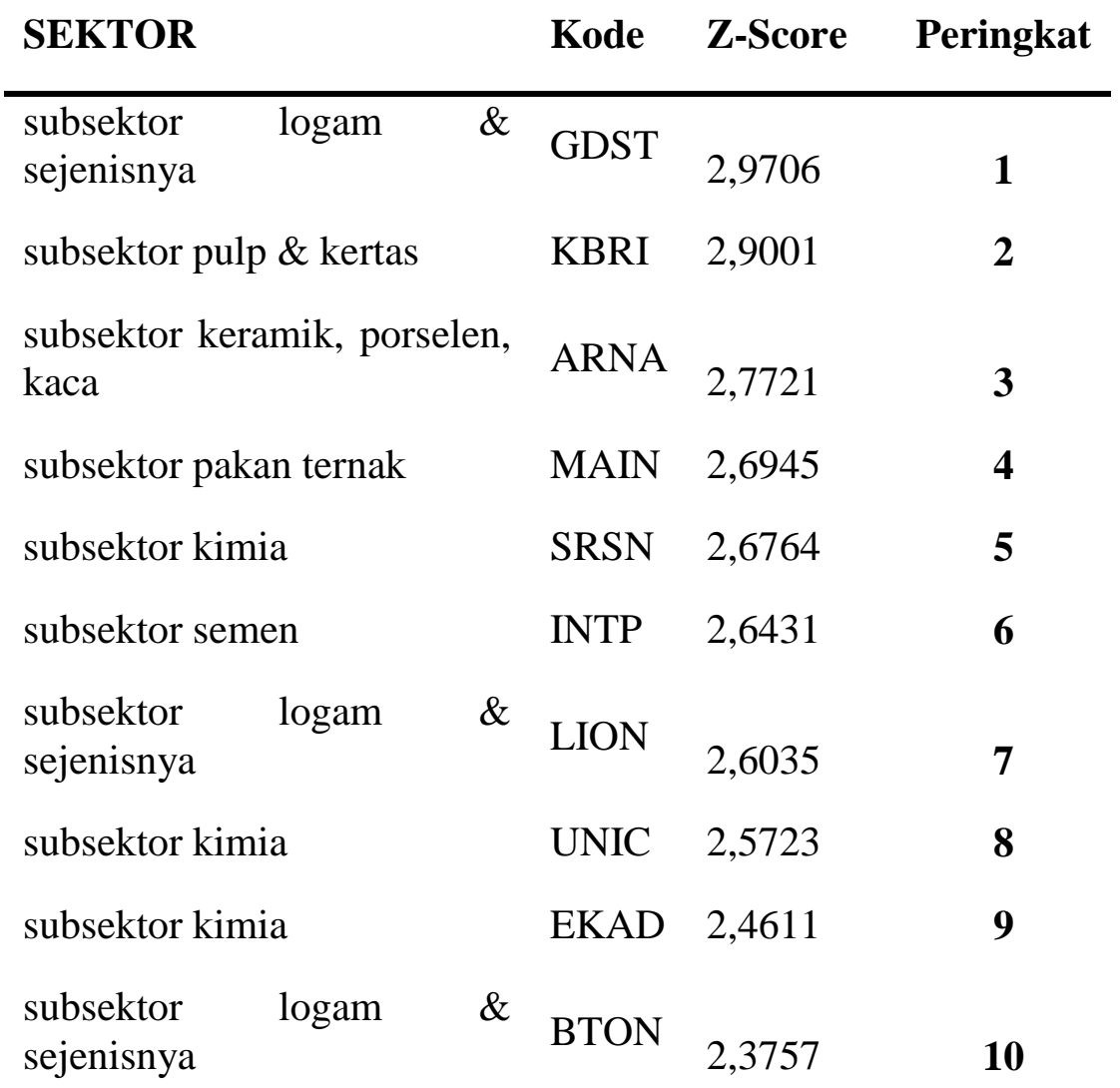




\begin{tabular}{llll}
$\begin{array}{l}\text { subsektor keramik, porselen, } \\
\text { kaca }\end{array}$ & TOTO & 2,2959 & $\mathbf{1 1}$ \\
$\begin{array}{l}\text { subsektor keramik, porselen, } \\
\text { kaca }\end{array}$ & $\begin{array}{l}\text { AMF } \\
\text { G }\end{array}$ & 2,2934 & $\mathbf{1 2}$ \\
$\begin{array}{l}\text { subsektor logam \& } \\
\text { sejenisnya }\end{array}$ & CTBN & 2,1495 & $\mathbf{1 3}$ \\
subsektor semen & SMGR & 2,1367 & $\mathbf{1 4}$ \\
subsektor pakan ternak & JPFA & 2,0351 & $\mathbf{1 5}$ \\
subsektor pulp \& kertas & ALDO & 1,9958 & $\mathbf{1 6}$ \\
subsektor plastik \& kemasan & FPNI & 1,9585 & $\mathbf{1 7}$ \\
subsektor plastik \& kemasan & APLI & 1,9283 & $\mathbf{1 8}$ \\
& & \multicolumn{2}{c}{ Sumber: olah data }
\end{tabular}

Pada tabel 4.3. tersebut dengan kode GDST yakni PT. Gunawan Dianjaya Steel Tbkpada subsektor logam \& sejenisnya memiliki nilai z-score 2,9706 dengan indikasi 1,81 - 2,99 yang terletak di posisi grey area dan menduduki peringkat/ rangking pertama tertinggi pada perusahaan manufaktur tahun 2013, sedangkan PT. Asiaplast Industries Tbk dengan kode APLI pada subsektor plastik\&kemasan memiliki nilai z-score 1,9283 dengan indikasi 1,81 - 2,99 yang terletak di posisi yang dan menduduki peringkat/ rangking ke 18 pada tahun 2013.

Tabel 4.4. Hasil index peringkat indikasi Grey Area tahun 2014

\begin{tabular}{lllc} 
SEKTOR & Kode & $\begin{array}{l}\text { Z- } \\
\text { Score }\end{array}$ & Peringkat \\
\hline subsektor plastik \& kemasan & APLI & 2,8984 & $\mathbf{1}$ \\
subsektor keramik, porselen, & ARNA & 2,8981 & $\mathbf{2}$ \\
kaca & UNIC & 2,6239 & $\mathbf{3}$ \\
subsektor kimia & DPNS & 2,5935 & $\mathbf{4}$ \\
subsektor kimia & EKAD & 2,5865 & $\mathbf{5}$ \\
subsektor kimia & FPNI & 2,5765 & $\mathbf{6}$ \\
subsektor plastik \& kemasan & INTP & 2,5326 & $\mathbf{7}$ \\
subsektor semen & SRSN & 2,4899 & $\mathbf{8}$ \\
subsektor kimia & &
\end{tabular}




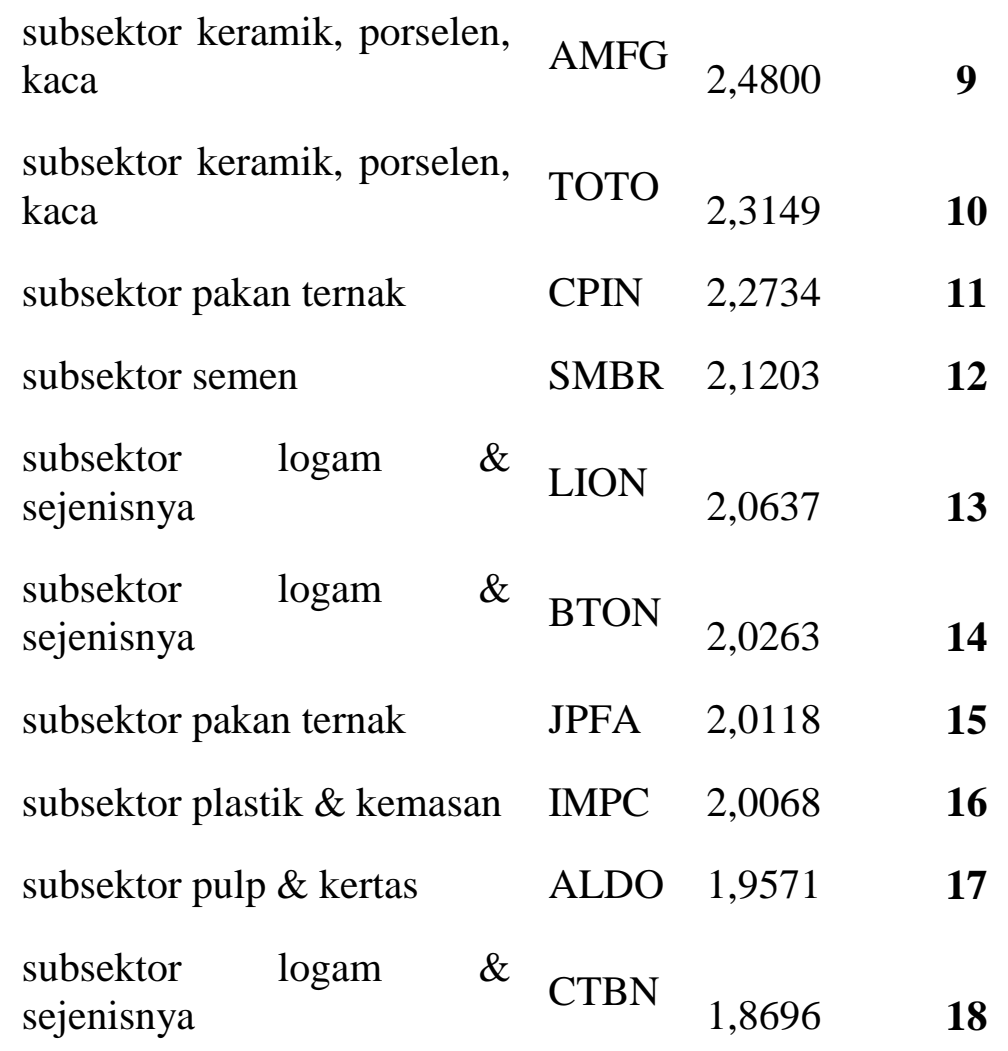

Sumber: olah data

Pada tabel 4.4. tersebut dengan kode APLI yakni PT. Asiaplast Industries Tbkpada subsektor plastik \& kemasan memiliki nilai z-score 2,8984 dengan indikasi 1,81 - 2,99 yang terletak di posisi grey area dan menduduki peringkat/ rangking pertama tertinggi pada perusahaan industry dasar dan kimia tahun 2014, sedangkan PT. Citra Tubindo Tbk dengan kode CTBN pada subsektor logam \& sejenisnya memiliki nilai z-score 1, 8696 dengan indikasi 1,81 - 2,99 yang terletak di posisi yang dan menduduki peringkat/ rangking ke 18 pada perusahaan industri dasar dan kimia tahun 2014.

Tabel 4.5. Hasil index peringkat indikasi bangkrut tahun 2013

\begin{tabular}{|c|c|c|c|c|c|}
\hline \multicolumn{3}{|c|}{ SEKTOR } & Kode & Z-Score & $\underset{t}{\text { Peringka }}$ \\
\hline \multirow{2}{*}{\multicolumn{3}{|c|}{ subsektor plastik \& kemasan }} & IMPC & 1,7567 & 1 \\
\hline & & & TPIA & 1,7238 & 2 \\
\hline \multicolumn{3}{|c|}{ subsektor semen } & SMBR & 1,7212 & 3 \\
\hline $\begin{array}{l}\text { subsektor } \\
\text { sejenisnya }\end{array}$ & logam & $\&$ & NIKL & 1,6478 & 4 \\
\hline $\begin{array}{l}\text { subsektor } \\
\text { sejenisnya }\end{array}$ & logam & $\&$ & PICO & 1,5742 & 5 \\
\hline subsektor $k$ & & & BUDI & 1,3716 & 6 \\
\hline subsektor $\mathrm{k}$ & & & BRPT & 1,3637 & 7 \\
\hline
\end{tabular}




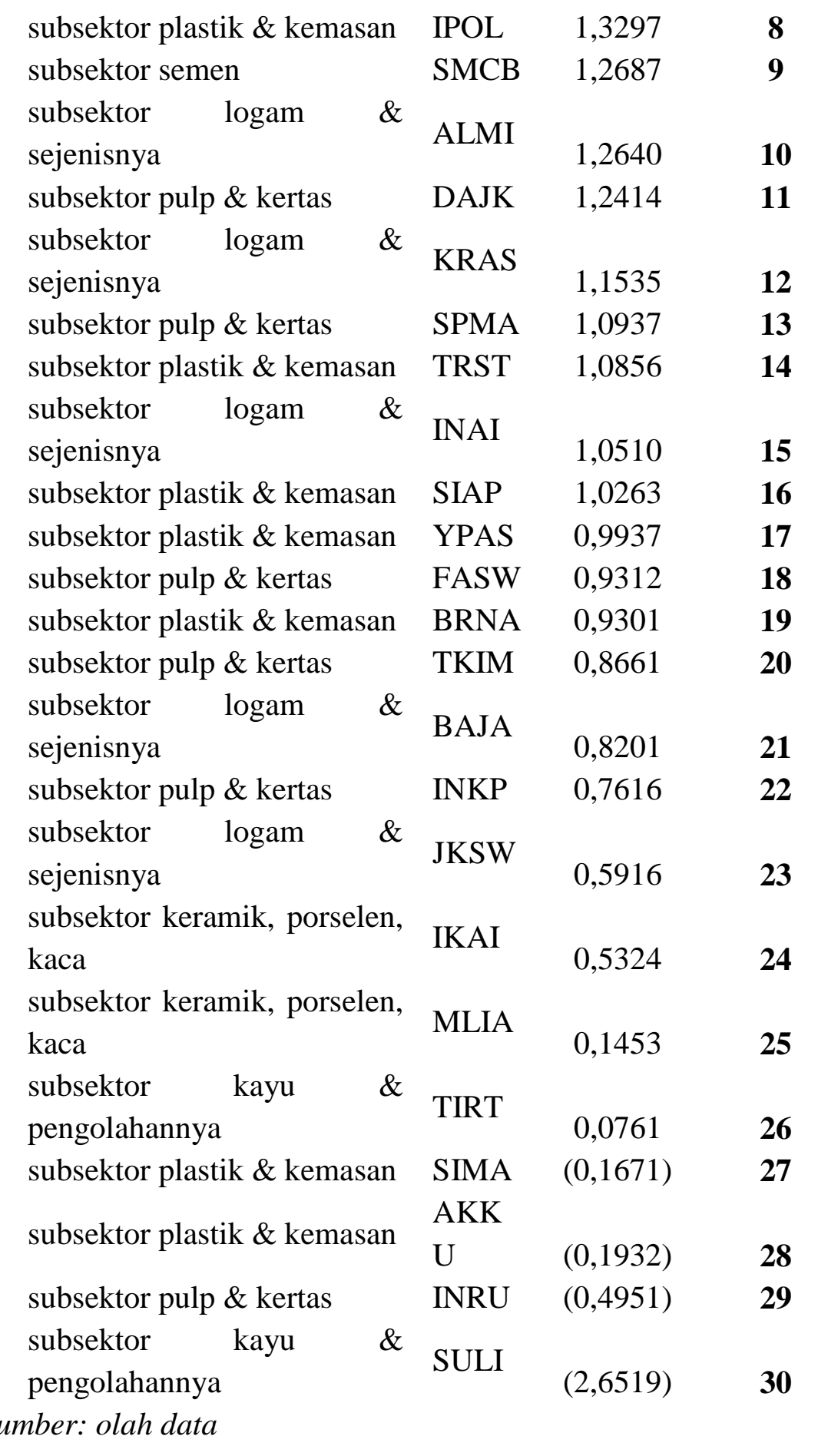

Pada tabel 4.5. tersebut dengan kode IMPC yakni PT. Impack Pratama Industri Tbkpada subsector plastic \& kemasan memiliki nilai z-score 1,7567 dengan indikasi $<1,81$ yang terletak di posisi bangkrut dan menduduki peringkat/ rangking pertama tertinggi pada tahun 2013, sedangkan dengan kode SULI yakni PT. SJL Global Tbk pada subsektor kayu\&pengolahannya memiliki nilai z-score $(2,6519)$ dengan indikasi < 1,81yang terletak di posisi yang dan menduduki peringkat/ rangking ke 30 pada tahun 2013. 
Tabel 4.6. Hasil index peringkat indikasi bangkrut tahun 2014

\begin{tabular}{|c|c|c|c|}
\hline SEKTOR & Kode & $\begin{array}{l}\text { Z- } \\
\text { Score }\end{array}$ & $\begin{array}{l}\text { Peringk } \\
\text { at }\end{array}$ \\
\hline subsektor kimia & TPIA & 1,7036 & 1 \\
\hline subsektor logam \& sejenisnya & PICO & 1,6863 & 2 \\
\hline subsektor logam \& sejenisnya & GDST & 1,661 & 3 \\
\hline subsektor plastik \& kemasan & YPAS & 1,5703 & 4 \\
\hline subsektor pakan ternak & MAIN & 1,4044 & 5 \\
\hline subsektor kimia & BRPT & 1,3979 & 6 \\
\hline subsektor plastik \& kemasan & TRST & 1,3597 & 7 \\
\hline subsektor logam \& sejenisnya & NIKL & 1,3282 & 8 \\
\hline subsektor pulp \& kertas & DAJK & 1,3046 & 9 \\
\hline subsektor plastik \& kemasan & BRNA & 1,3016 & 10 \\
\hline subsektor pulp \& kertas & SPMA & 1,2840 & 11 \\
\hline subsektor logam \& sejenisnya & BAJA & 1,2765 & 12 \\
\hline subsektor logam \& sejenisnya & INAI & 1,2710 & 13 \\
\hline subsektor plastik \& kemasan & IPOL & 1,2465 & 14 \\
\hline subsektor pulp \& kertas & FASW & 1,2333 & 15 \\
\hline subsektor kayu \& pengolahannya & TIRT & 1,2115 & 16 \\
\hline subsektor kimia & BUDI & 1,2099 & 17 \\
\hline subsektor logam \& sejenisnya & ALMI & 1,1612 & 18 \\
\hline subsektor logam \& sejenisnya & KRAS & 1,0439 & 19 \\
\hline subsektor semen & SMCB & 1,0374 & 20 \\
\hline subsektor keramik, porselen, kaca & MLIA & 0,8954 & 21 \\
\hline subsektor pulp \& kertas & TKIM & 0,8175 & 22 \\
\hline subsektor pulp \& kertas & INKP & 0,7650 & 23 \\
\hline
\end{tabular}




\begin{tabular}{|c|c|c|}
\hline subsektor plastik \& kemasan & SIMA & 0,5914 \\
\hline subsektor logam \& sejenisnya & JKSW & 0,4602 \\
\hline subsektor keramik, porselen, kaca & IKAI & 0,1182 \\
\hline subsektor plastik \& kemasan & AKKU & $\begin{array}{l}(0,105 \\
5)\end{array}$ \\
\hline subsektor pulp \& kertas & INRU & $\begin{array}{l}(0,398 \\
7)\end{array}$ \\
\hline subsektor pulp \& kertas & KBRI & $\begin{array}{l}(0,732 \\
7)\end{array}$ \\
\hline subsektor kayu \& pengo & SULI & $\begin{array}{l}(0,917 \\
9)\end{array}$ \\
\hline
\end{tabular}

Sumber: olah data

Pada tabel 4.3. dengan kode TPIA yakni PT. Chandra Asri Petrochemical Tbk pada subsector kimia memiliki nilai z-score 1,7036 dengan indikasi $<1,81$ yang terletak di posisi bangkrut dan menduduki peringkat/ rangking pertama pada perusahaan industry dasar dan kimia tahun 2014, sedangkan kode SULI yakni PT. SLJ Global Tbk pada subsektor kayu \& pengolahannya memiliki nilai z-score $(0,9179)$ dengan indikasi < 1,81yang terletak di posisi bangkrut yang dan menduduki peringkat/ rangking ke 30 paling rendah pada perusahaan industri dasar dan kimia tahun 2014.

Tabel 4.7. persentase

Indikasi Tahun $2013 \quad$ Tahun 2014

\begin{tabular}{lll}
\hline Sehat & $(9 / 57 * 100 \%)=15,8 \%$ & $(9 / 57 * 100 \%)=15,8 \%$ \\
Grey area & $(18 / 57 * 100 \%)=31,6 \%$ & $(18 / 57 * 100 \%)=31,6 \%$ \\
Bangkrut & $(30 / 57 * 100 \%)=52,6 \%$ & $(30 / 57 * 100 \%)=52,6 \%$
\end{tabular}

Sumber: olah data

Berdasarkan hasil penelitian yang telah dilakukan oleh peneliti mengenai indikasi kebangkrutan dengan metode Altman Z-Score pada tabel 4.7. menunjukkan bahwa pada tahun 2013 dan tahun 2014 di BEI ada 57 perusahaan industri dasar dan kimia dengan berbagai sektor dengan persentase $52,6 \%$ di posisi bangkrut dan $31,6 \%$ di posisi grey area serta $15,8 \%$ di posisi sehat. Posisi sehat lebih kecil dari pada yang lainnya, hal ini menunjukkan cenderung kurang baik pada perusahaan industri dasar dan kimia di BEI. 


\subsection{Analisis Kesesuaian dengan Kenyataan Sebenarnya}

Tabel 4.8. Tingkat Kesesuaian dengan Kenyataan Sebenarnya tahun 2013

\begin{tabular}{|c|c|c|c|c|}
\hline No & Kode & $\begin{array}{l}\text { Z-Score } \\
2013\end{array}$ & $\begin{array}{l}\text { Tahun } 2014 \\
\text { bangkrut } \\
\text { bangkrut }\end{array}$ & tidak \\
\hline 1 & INCI & Sehat & tidak bangkrut & \\
\hline 2 & ALKA & Sehat & tidak bangkrut & \\
\hline 3 & JPRS & Sehat & tidak bangkrut & \\
\hline 4 & KIAS & Sehat & tidak bangkrut & \\
\hline 5 & DPNS & Sehat & tidak bangkrut & \\
\hline 6 & TBMS & Sehat & tidak bangkrut & \\
\hline 7 & IGAR & Sehat & tidak bangkrut & \\
\hline 8 & LMSH & Sehat & tidak bangkrut & \\
\hline 9 & CPIN & Sehat & tidak bangkrut & \\
\hline No & GDST & grey area & tidak bangkrut & \\
\hline 11 & KBRI & grey area & tidak bangkrut & \\
\hline 12 & ARNA & grey area & tidak bangkrut & \\
\hline 13 & MAIN & grey area & tidak bangkrut & \\
\hline 14 & SRSN & grey area & tidak bangkrut & \\
\hline 15 & INTP & grey area & tidak bangkrut & \\
\hline 16 & LION & grey area & tidak bangkrut & \\
\hline 17 & UNIC & grey area & tidak bangkrut & \\
\hline 18 & EKAD & grey area & tidak bangkrut & \\
\hline 19 & BTON & grey area & tidak bangkrut & \\
\hline
\end{tabular}




\begin{tabular}{|c|c|c|c|}
\hline 0 & TOTO & grey area & tidak bangkrut \\
\hline & AMFG & grey area & tidak bangkrut \\
\hline 2 & CTBN & grey area & tidak bangkrut \\
\hline & SMGR & grey area & tidak bangkrut \\
\hline & JPFA & grey area & tidak bangkrut \\
\hline & ALDO & grey area & tidak bangkrut \\
\hline & FPNI & grey area & tidak bangkrut \\
\hline & APLI & grey area & tidak bangkrut \\
\hline & IMPC & bangkrut & tidak bangkrut \\
\hline 9 & TPIA & bangkrut & tidak bangkrut \\
\hline 30 & SMBR & bangkrut & tidak bangkrut \\
\hline 31 & NIKL & bangkrut & tidak bangkrut \\
\hline$J 2$ & $\mathrm{PICO}$ & bangkrut & tidak bangkrut \\
\hline 33 & BUDI & bangkrut & tidak bangkrut \\
\hline 34 & BRPT & bangkrut & tidak bangkrut \\
\hline 35 & IPOL & bangkrut & tidak bangkrut \\
\hline 36 & SMCB & bangkrut & tidak bangkrut \\
\hline 37 & ALMI & bangkrut & tidak bangkrut \\
\hline 38 & DAJK & bangkrut & tidak bangkrut \\
\hline 39 & KRAS & bangkrut & tidak bangkrut \\
\hline 40 & SPMA & bangkrut & tidak bangkrut \\
\hline 41 & TRST & bangkrut & tidak bangkrut \\
\hline 42 & INAI & bangkrut & tidak bangkrut \\
\hline 43 & SIAP & bangkrut & tidak bangkrut \\
\hline 44 & YPAS & bangkrut & tidak bangkrut \\
\hline 45 & FASW & bangkrut & tidak bangkrut \\
\hline 46 & BRNA & bangkrut & tidak bangkrut \\
\hline 4 & TKIM & bangk & tidak bangk \\
\hline
\end{tabular}




$\begin{array}{llll}48 & \text { BAJA } & \text { bangkrut } & \text { tidak bangkrut } \\ 49 & \text { INKP } & \text { bangkrut } & \text { tidak bangkrut } \\ 50 & \text { JKSW } & \text { bangkrut } & \text { tidak bangkrut } \\ 51 & \text { IKAI } & \text { bangkrut } & \text { tidak bangkrut } \\ 52 & \text { MLIA } & \text { bangkrut } & \text { tidak bangkrut } \\ 53 & \text { TIRT } & \text { bangkrut } & \text { tidak bangkrut } \\ 54 & \text { SIMA } & \text { bangkrut } & \text { tidak bangkrut } \\ 55 & \text { AKKU } & \text { bangkrut } & \text { tidak bangkrut } \\ 56 & \text { INRU } & \text { Bangkrut } & \text { tidak bangkrut } \\ 57 & \text { SULI } & \text { Bangkrut } & \text { tidak bangkrut }\end{array}$

Tabel 4.9. Tingkat Kesesuaian dengan Kenyataan Sebenarnya tahun 2014

\begin{tabular}{llll} 
No & Kode & $\begin{array}{l}\text { Z-Score } \\
\mathbf{2 0 1 4}\end{array}$ & $\begin{array}{l}\text { Tahun 2015 } \\
\text { bangkrut / tidak } \\
\text { bangkrut }\end{array}$ \\
\hline 1 & ALKA & Sehat & tidak bangkrut \\
2 & INCI & Sehat & tidak bangkrut \\
3 & SIAP & Sehat & tidak bangkrut \\
4 & KIAS & Sehat & tidak bangkrut \\
5 & IGAR & Sehat & tidak bangkrut \\
6 & JPRS & Sehat & tidak bangkrut \\
7 & SMBR & Sehat & tidak bangkrut \\
8 & TBMS & Sehat & tidak bangkrut \\
9 & LMSH & Sehat & tidak bangkrut \\
10 & APLI & grey area & tidak bangkrut \\
11 & ARNA & grey area & tidak bangkrut
\end{tabular}


12 UNIC grey area tidak bangkrut

13 DPNS grey area tidak bangkrut

14 EKAD grey area tidak bangkrut

15 FPNI grey area tidak bangkrut

16 INTP grey area tidak bangkrut

17 SRSN grey area tidak bangkrut

18 AMFG grey area tidak bangkrut

19 TOTO grey area tidak bangkrut

20 CPIN grey area tidak bangkrut

21 SMBR grey area tidak bangkrut

22 LION grey area tidak bangkrut

23 BTON grey area tidak bangkrut

24 JPFA grey area tidak bangkrut

25 IMPC grey area tidak bangkrut

26 ALDO grey area tidak bangkrut

27 CTBN grey area tidak bangkrut

28 TPIA bangkrut tidak bangkrut

29 PICO bangkrut tidak bangkrut

30 GDST bangkrut tidak bangkrut

31 YPAS bangkrut tidak bangkrut

32 MAIN bangkrut tidak bangkrut

33 BRPT bangkrut tidak bangkrut

34 TRST bangkrut tidak bangkrut

35 NIKL bangkrut tidak bangkrut

36 DAJK bangkrut tidak bangkrut

37 BRNA bangkrut tidak bangkrut

38 SPMA bangkrut tidak bangkrut

39 BAJA bangkrut tidak bangkrut 


$\begin{array}{llll}40 & \text { INAI } & \text { bangkrut } & \text { tidak bangkrut } \\ 41 & \text { IPOL } & \text { bangkrut } & \text { tidak bangkrut } \\ 42 & \text { FASW } & \text { bangkrut } & \text { tidak bangkrut } \\ 43 & \text { TIRT } & \text { bangkrut } & \text { tidak bangkrut } \\ 44 & \text { BUDI } & \text { bangkrut } & \text { tidak bangkrut } \\ 45 & \text { ALMI } & \text { bangkrut } & \text { tidak bangkrut } \\ 46 & \text { KRAS } & \text { bangkrut } & \text { tidak bangkrut } \\ 47 & \text { SMCB } & \text { bangkrut } & \text { tidak bangkrut } \\ 48 & \text { MLIA } & \text { bangkrut } & \text { tidak bangkrut } \\ 49 & \text { TKIM } & \text { bangkrut } & \text { tidak bangkrut } \\ 50 & \text { INKP } & \text { bangkrut } & \text { tidak bangkrut } \\ 51 & \text { SIMA } & \text { bangkrut } & \text { tidak bangkrut } \\ 52 & \text { JKSW } & \text { bangkrut } & \text { tidak bangkrut } \\ 53 & \text { IKAI } & \text { bangkrut } & \text { tidak bangkrut } \\ 54 & \text { AKKU } & \text { bangkrut } & \text { tidak bangkrut } \\ 55 & \text { INRU } & \text { bangkrut } & \text { tidak bangkrut } \\ 56 & \text { KBRI } & \text { bangkrut } & \text { tidak bangkrut } \\ 57 & \text { SULI } & \text { bangkrut } & \text { tidak bangkrut }\end{array}$

Berdasarkan pada tabel 4.8 dan tabel 4.9 tersebut,kenyataannya sampai sekarang ini operasi perusahaan masih berjalan normal dan perusahaan dikatakan dalam kondisi berjalan dengan baik setelah peneliti mengamati. Hal ini tidak terdapat kesesuaian hasil index dengan kondisi kenyataan sebenarnya. Maka hasil index model altman $\mathrm{z}$-score tidak dapat digunakan sebagai alat indikasi kecendrungan kebangkrutan perusahaan.

\section{SIMPULAN DAN SARAN}

\subsection{Keterbatasan Penelitian}

Dalam penelitian ini terdapat keterbatasan yang dapat dijadikan bahan pertimbangan bagi peneliti berikutnya agar mendapatkan hasil yang lebih baik. Berikut keterbatasan penelitian yaitu: 
a. hasil analisa altman z-score sangat terkait dengan terbatasnya jumlah sampel dan data serta periode yang digunakan. Sehingga penelitian ini tidak mampu untuk menganalisa secara keseluruhan dimana hasil analisa altman z-score terbatas pada perusahaan industri dasar dan kimia saja sehingga hanya menggambarkan kondisi pada perusahaan industry dasar dan kimia saja.

b. Periode pengamatan hanya dua tahun, mungkin akan berbeda jika digunakan periode pengamatan yang berbeda ataupun lebih panjang.

c. Dan model yg digunakan hanya Altman Z-Score saja dimana terdapat beberapa model-model untuk analisa kebangkrutan, mungkin akan berbeda jika menggunakan model lain atau menggunakan beberapa model dalam menganalisa.

\subsection{Simpulan}

1. Hasil index Z-Score pada perusahaan industri dasar dan kimia tahun 2013 diduduki oleh PT. Intan Wijaya Internasional Tbkpada subsector kimia dengan peringkat pertama tertinggi dengan kondisi sehat, sedangkan yang menduduki peringkat paling terakhir dan terendah di perusahaan industri dasar dan kimia di BEI adalah PT. SLJ Global Tbk pada subsektor kayu \& pengolahannya dengan kondisi bangkrut. Hasil index Z-Score pada perusahaan industri dasar dan kimia tahun 2014 diduduki oleh PT. Alakasa Industrindo Tbk pada subsector logam dan sejenisnya dengan peringkat pertama tertinggi dengan kondisi sehat, sedangkan yang menduduki peringkat paling terakhir dan terendah di perusahaan industri dasar dan kimia di BEI adalah PT. SLJ Global Tbk pada subsektor kayu \& pengolahannya dengan kondisi bangkrut.

2. Hasil penelitian ini tidak konsisten/ sesuai dengan kenyataan sebenarnya yang menunjukkan bahwa metode altman tidak dapat dijadikan alat untuk mengindikasikan kecendrungan terhadap kebangkrutan.

\subsection{Saran}

Saran yang dapat diberikan setelah melakukan penelitian ini adalah:

1. Saran untuk perusahaan industri dasar dan kimia

Sebaiknya perusahaan selalu memelihara dan meningkatkan kinerja perusahaan secara lebih baik lagi, karena berdasarkan hasil pada tahun2013 dan 2014 sebagian besar perusahaan-perusahaan yang dijadikan sampel berpotensi untuk mengalami indikasi kebangkrutan dengan nilai Z-Sore dibawah nilai 1,81 . 
Bagi perusahaan industri dasar dan kimia pada model altman z-score ini tidak dapat digunakan untuk mengindikasikan kebangkrutan karena adanya ketidaksesuaian dengan kenyataannya, namun model ini dapat membantu untuk menilai dan memberi masukan untuk perbaikan dan mempertahankan perusahaan.

2. Saran Penelitian Lanjutannya:

Peneliti menyadari bahwa penelitian ini masih jauh dari sempurna. Untuk itu peneliti memberikan saran untuk penelitian lanjutannya yakni sebaiknya jumlah sampel dan periode penelitian yang digunakan ditambah sehingga menghasilkan informasi yang lebih baik. Diharapkan mampu menganalisa variabel lainnya yang tidak terkontrol pada penelitian ini atau gunakan berbagai model untuk analisis kebangkrutan seperti model springate, fulmer, blasztk, dll

\section{DAFTAR PUSTAKA}

Brigham, Eugene F \& J. Fred Weston. (2005). Manajemen Keuangan. Erlangga. Jakarta.

Jaya, Asmara Ketut. (2014). Laporan Keuangan merupakan Alat dalam Memprediksi Kecendrungan Terjadinya Kebangkrutan Perusahaan dengan Menggunakan Model ALTMAN (studi analisis). Jurnal Akuntansi FE Untar. Volume XVIII/02/Mei/2014. Nomor 02 hal 166-187.

Lyn. M, Fraser dan Aileen Ormiston. (2008). Memahami Laporan Keuangan. PT. Indeks. Jakarta.

Margaretha, Farah. (2005). Teori dan Aplikasi Manajemen Keuangan Investasi dan Sumber Dana Jangka Pendek. Grasindo Gramedia Widiasarana. Jakarta.

Silaban, Pasaman. (2014). Analisis Kebangkrutan dengan Menggunakan Model ALTMAN (Z-SCORE) Studi Kasus di Perusahaan Telekomunikasi. Jurnal Akuntansi FE Untar. Volume XVIII//03/September/ 2014. Nomor 03. hal 322-334.

Syafri, Sofyan Harahap. (2006). Analisis Kritis atas Laporan Keuangan. PT Raja Grafindo Persada. Jakarta.

Sekaran, Uma. (2006). Metodologi Penelitian untuk Bisnis. Edisi 4, Buku 2. Salemba Empat. Jakarta.

Usman, Nuralya. (2015). Analisis Prediksi Kebangkrutan Perusahaan dengan Menggunakan Model Altman Z-Score pada Perusahaan Manufaktur yang 
Terdaftar di BEI. Skripsi Strata-1 Manajemen. Fakultas Ekonomi Dan Bisnis Universitas Hasanuddin. Makasar.

www.idx.com. Diakses 1 Maret 2015

http://nasional.kontan.co.id/news/. Diakses 1 Maret 2015

http://www.kemenperin.go.id/. Diakses 1 Maret 2015 